\title{
Implication of EBOT Kit in Kuwait's Robotics Technology Learning and Innovation
}

\author{
Ahmad A A Alsaleh, Naser H N Jasem \\ Switching department, High institute of telecommunication and navigation /Public Authority for applied \\ education and training, Kuwait
}

\begin{abstract}
Despite being one of the highest ranking countries with respect to GDP per capita, Kuwait has not yet made its mark in the world of technology and research. Researchers suggest that due to its diverse nature, Robotics education can have a significant effect in the research and innovation of a country. Therefore advancements have been made all around the world to promote robotics education. Despite of the efforts made in Kuwait, robotics education is still on hold. The paper discusses the issues and obstacles in the implementation of robotics education in Kuwait and how a robotics kit "EBOT" is making an impact in the Kuwait's future education and innovation.
\end{abstract}

Keywords: Education, GUI, microcontroller, robotics, open source

\section{Introduction}

From the past two decades Robotics technology has emerged rapidly in the industry and in the domestic setup. Based on the statistics of International Federation of Robotics (IFR) the sales of professional service robots have reached its highest ever value in 2014, $11.5 \%$ more than 2013 and the sales of domestic robots has increased by $28 \%$ compared to 2013 and is expected to grow $12 \%$ each year during the next three years (Anon., 2015).The IFR also estimates the sale of domestic robots to reach about US $\$ 6.5$ billion from the year 2014 to 2017. During this period almost 3 million robots are expected to be sold for education and research purposes. This popularity in the field of robotics shows the future trend and importance of the robotics education. Some educators have claimed that through hands-on experimentation, robots help youth transform abstract science, engineering and technology (SET) concepts into concrete real-world understanding (Bradley S.Barker, 2007). Therefore most countries are now investing more and more in the development and education of robotics technology (Anon., 2015).

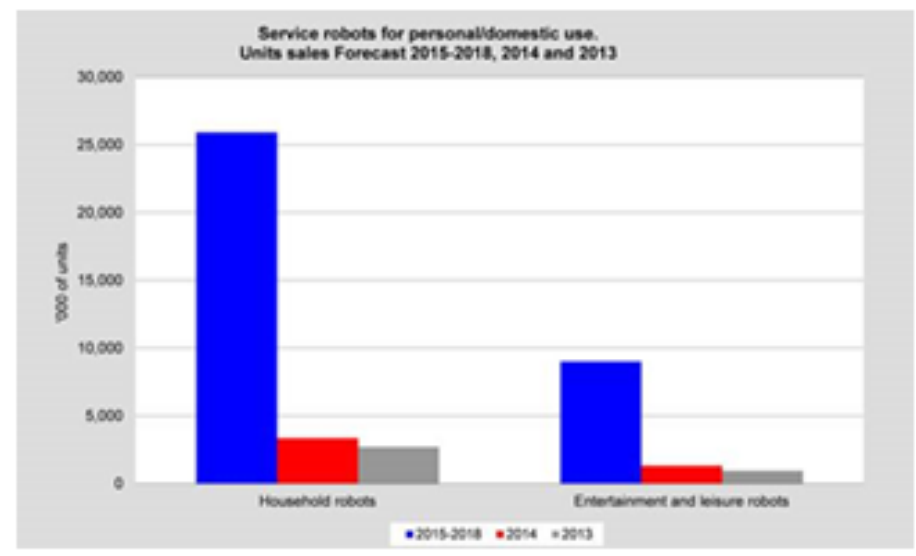

\section{Robotics Education}

Due do the diverse nature of robotic systems, its education includes a wide range of engineering disciplines including Mechanical, Electronics and Software. Therefore its educational curriculum can be divided into a few main modules which are as follows (Zhang, et al., 2008):

1. Introduction to Robotics

This module relates to the overview of robotics. It deals with the history of robotics and how the robots have evolved over the years into the lives of human beings. Topics such as human robot interaction and its social implications are also emphasised in this module.

2. Hardware of Robot

The structure and the mechanical principles are the main focus of this module. The basics of sensors, drives and control systems are mainly studied to understand the mechanics of robotics systems. 
3. Robot Programming

Since robotic systems comprise of microprocessors and embedded systems, programming is a vital part of robotics study. Different types of programming languages are taught in this module.

4. Implementation of Robotics

This module is focused on the applications of robotic systems in industries and domestic setup. Mainly the operation and maintenance of the systems is studied.

\section{Kuwait's Economy and its Robotics Education}

Kuwait is geographically small, but a wealthy country, with crude oil reserves of about 102 billion barrels, more than 6\% of world reserves (Anon., 2015).Kuwait has been one of the highest ranking countries with respect to Gross Domestic Product (GDP) per capita for the past 20 years (Anon., 2015) (Anon., 2015) (Anon., 2015). Petroleum accounts for over half of GDP, 94\% of export revenues, and $89 \%$ of government income. Despite Kuwait's dependence on oil, the government has cushioned itself against the impact of lower oil prices by continuous saving of at least $10 \%$ of government revenue in the Fund for Future Generations (Anon., 2015). Despite these savings, Kuwait has not yet been able to mark its ground in technology and innovation. Based on the Global Creativity Index (GCI) report Kuwait does not rank in the top 80 countries in innovation, technology, talent and research (Richard Florida, 2010).

Where many countries are investing largely on robotics education due to its abstract engineering principles (Anon., 2015), the trend of robotics education has not been seen in Kuwait. Some efforts have been made in the previous years but have not yet succeeded to accomplish a sustainable goal.

\section{Issues and Obstacles}

1. The emphasis on robotics competitions rather than robotics education.

For many years a trend has been seen in a number of countries where robotics competitions have been used to promote robotics education. This effort has not lead to a positive impact in the learning process as it has not been implemented properly in most cases. The reasons of its failure are as follows:

- The ambiguous goal of robotics competitions.

- The hardware part of the project is more emphasized when the completions are held thus limiting the essences of the robotics education, its programming.

- The significance of wining has a negative impact on the learning process.

- The number of students benefitting from the competitions is limited as only the students participating the competition go through the complete learning process.

- Due the projects being in groups not all students learn every aspect of the project.

- The commercial elements of the competition lead to a negative impact as students sometimes are forced to take an unscientific approach.

2. Software complexity of the robotics systems

Since robotics systems comprises of both the hardware and software elements its learning process becomes difficult. Programming itself is considered challenging and difficult for most students. It has been seen that most students in programming course show low confidence (Ioanna Stamouli, 2004). The process of learning programming is considered to be similar of learning a new language. Thus this complexity of software development has restrained the rapid implementation of robotics education.

3. Lack of an organized Open-Source Platform

In the past decade open source platforms have gained huge popularity due to their straight forward nature. These platforms have a number of advantages including customizability, freedom and cost. Open source platforms are not limited by the company's efforts and thus the cycle of learning is not broken at any stage. Many of the current available learning platforms are not open source such as LEGO NXT, thus limiting the learning process. On the other hand open source platforms have been around for a while but due to their open nature they are hard to follow many of the times. Thus the implementation of an organized open source platform which is easy to understand for the user is yet to be seen, specifically in Kuwait.

\section{EBOT Kit}

The E- Robot Kit is a smart solution for the robotics learning. It was built as a necessity to increase the members of the MAKER movement that could take part in the building of future technology. EBOT is a Do - It - Yourself robotics platform and Arduino compatible framework. It comes with new concepts about DIY electronics with extendable functionality that's not limited to certain modules. It also introduces resources and methods to inspire the next generation of scientists, engineers, artists and designers. The development of this kit was directed towards the students, which teaches them the following aspects:

- Use of applied STEM (Science- Technology- Engineering- Math)

- Problem solving 
- $\quad$ Creative solutions

- $\quad$ Logical and Critical thinking

- Elements of Mechanical and Electronic Systems

- $\quad$ Programming Logic and Coding

\section{The Software}

One of the main elements of EBOT it is its software. The Hardware can be programmed through a laptop or android tablet using visual programming with automatic code generation or directly edited code. Each input or output for EBOT is called a node where all sensors are included as nodes. EBOT is a multi-tasking platform, it can execute two routines at the same time. Moreover EBOT uses Arduino codes and libraries. The main features of the software are as follows:

- $\quad$ Drag and drop visual programming

- $\quad$ Auto generation of code

- Arduino Compatible

- $\quad$ Multi-tasking

- $\quad$ Node Designer, where customized sensors could be added to the projects

- Data Lab where the data received could be processed visualized and stored.

VII. Strategy

Table 1 Distribution of Robotics Education in different stages of School

\begin{tabular}{|l|l|ll|}
\hline- & School & \multicolumn{2}{|l|}{ Elements of Robotics Education } \\
\hline $\mathbf{1}$ & Kindergarten & - & Hardware (simple) \\
\hline $\mathbf{2}$ & Elementary School & - & Introduction to Robotics (simple) \\
& & - & Hardware (simple) \\
\hline $\mathbf{3}$ & Secondary School & - & Introduction to Robotics (moderate) \\
& & - & Hardware (moderate) \\
& & - & Programming Logic (Visual) \\
\hline $\mathbf{4}$ & High School & - & Introduction to Robotics (Normal) \\
& & - & Hardware (Normal) \\
& & - & Programming (Code) \\
\hline $\mathbf{5}$ & University & - & Introduction to Robotics (Advance) \\
& & - & Hardware (Advance) \\
& & - & Programming (Advance) \\
\hline
\end{tabular}

\section{Kindergarten school approach:}

The goals:

1- Visualize the real life structures

2- Build small plastic structures

3- Learn to follow steps

4- Learn to use building blocks

Elementary School Approach:

The goals:

1- Build medium plastic structures

2- Solution Finding

3- Learn about microcontrollers and sensors

In this stage some basic understanding of the microcontroller unit is also. For the control unit a preprogrammed microcontroller unit is to be used.

\section{Secondary Schools Approach:}

The goals:

1- Visualize the real life structures and STEM

2- Build metal structures with screws and tools

3- Introduction to electronics

4- Learn the logic of programming

At this stage the students start programming the microcontroller using a simplified ladder programming to create sophisticated designs and robots. Student also will learn how to use sensors and program the remote control specials functions. Student will start with the simple plastic blocks and covered (Plastic Protected) Arduino microcontroller board, then slowly upgrade to building metal aluminum structures and get exposed to the real Arduino circuit board. 


\section{High School Approach:}

The goals:

1- Learn STEM (Science- Technology- Engineering- Math)

2- Programming Basics/ understanding Code

3- Design and Implementation of Complete projects

4- Problem solving

College and University level approach:

The goals:

- Research Oriented Projects

- Cross platform development e.g. Matlab, Visual Studio etc.

\section{Results}

The development of EBOT kit has been neutralizing the negative effects of the robotics competitions by adding more value to the learning phase rather than the competition phase. Not only the amount of teaching has increased but also the element of fun has increased the efficiency of the learning process. Unlike the robotics competitions the EBOT kit allows a structured learning process which emphasizes on each and every element of robotics education, thus aiding in the increase of innovation and creativity.

Due to the simplicity of the EBOT software the gap between the innovative and programming community is shortened. Instead of learning difficult syntax of different languages now the focus has been shifted to the logical part of Programming. This has opened up a wide range of opportunities. Now the teachers with non-programing background are being taught the logic of programming which in turn hugely benefits the students. This idea has had a significant impact as directly teaching programming logic to the student's through professional programmers is a very slow process (due to less amount of professionals available). Due to this advancement the reach of logical programming teaching has massively increased. A total number of 1484 teachers have being taught to use the E- Robot kit which are now teaching the students. Table 2 shows the statistics of teachers being taught in Kuwait using the E Robot Kit and Software since 2012.

Table 2 Statistics of Teachers being taught the use of E-Robot Kit and Software

\begin{tabular}{|l|l|l|l|}
\hline \multirow{2}{*}{ Year } & \multicolumn{3}{|l|}{ No. of Teachers taught of } \\
\cline { 2 - 4 } & Elementary School & Middle School & Total \\
\hline 2012 & 185 & 312 & 497 \\
\hline 2013 & 140 & 272 & 412 \\
\hline 2014 & 60 & 350 & 410 \\
\hline 2015 & 50 & 115 & 165 \\
\hline
\end{tabular}

This rapid increase in the teaching process of teachers has led to the addition of EBOT kit as a core subject in 15 schools of Kuwait. Moreover around 200 schools have added the EBOT kit in their extra curricular activities.

Because of its open source nature the EBOT has increased the previously shortened span of the learning process. Despite the massive availability of open source platforms, their reach to the students was restrictive because of lack of organization. Students often find the open source platforms hard to follow as they are not properly documented. EBOT has solved this problem by bring forth a platform which is not only open source but is also well organized and structured. Thus the learning cycle is not broken through out.

\section{Conclusion}

Kuwait has been lacking behind in the technology and innovation despite being a rich country. The recent development of a Robotics Education Kit "EBOT" has allowed the country to take its first step towards a better future. Due to its diverse and easy to use nature the kit is gaining popularity and has already reached to a few schools as core subject. Other initiatives such as the teaching of teachers to increase the reach of robotics education have been successfully implemented and are causing a positive impact in the learning process. Since 2012 around 1400 teachers have being taught how to use and program the E- Robot Kit. Due to this success a total of 15 schools have started teaching the EBOT Kit as a core subject, whereas about 200 schools teach it as an extra curricular activity. The kit encountered the problems created by previous attempts such as focus on robotics competitions rather than education, complexity of robot programming and lack of organized open source platform.

\section{References}

[1]. Anon., 2015. GDP per capita. [Online] Available at: http://data. worldbank.org/indicator/NY. GDP.PCAP.PP. CD?order=wbapi_data value_2014+wbapi_data_value+wbapi_data_value-last\&sort=desc

[2]. Anon.,2015.IndustrialRobot Statistics. [Online]Available at: http:// www.ifr.org /industrial- robots/statistics/ [Accessed 2015] 
[3]. Anon., 2015. Investment Trends: The Rise of the Robots. [Online] Available at: https:// www.bnymellon.com/us/en/ourthinking/investment-trends-the-rise-of-the-robots.jsp

[4]. Anon., 2015. The World Factbook: Kuwait. [Online]Available at: https://www.cia.gov/library/publications/the-worldfactbook/geos/ku.html

[5]. Anon., 2015. World Economic Outlook Database, October 2015. [Online] Available at: http://www.imf.org/ external/pubs/ft/weo/2015/02/weodata/weorept.aspx ?sy=2014\&ey=2014\&ssd=1\&sort=country\&ds=.\&br=1\&pr1.x=16\&pr1.y=7\&c $=512 \% 2 \mathrm{C} 668 \% 2 \mathrm{C} 914 \% 2 \mathrm{C} 672 \% 2 \mathrm{C} 612 \% 2 \mathrm{C} 946 \% 2 \mathrm{C} 614 \% 2 \mathrm{C} 137 \% 2 \mathrm{C} 311 \% 2 \mathrm{C} 962 \% 2 \mathrm{C} 213 \% 2 \mathrm{C} 674 \% 2 \mathrm{C} 911 \% 2 \mathrm{C} 676 \% 2 \mathrm{C} 193 \% 2$ C548\%2C122\%2C556\%2C $912 \% 2 \mathrm{C} 678 \% 2 \mathrm{C} 31$

[6]. Bradley S.Barker, J. A., 2007. Robotics as Means to Increase Achievement Scores in an Informal Learning Environment. Journal of Research on Technology in Education,, 39(3), pp. 229-243.

[7]. Ioanna Stamouli, E. D. ,. a. M. H., 2004. Establishing Structured Support for Programming Students. s.l., s.n.

[8]. Richard Florida, C. M. S. S. M. H., 2010. Creativity and Prosperity: The Global Creativity Index, s.1.: The Martin Prosperity Institute.

[9]. Zhang, G., Sch. of Teacher Educ., Z. N. U. Z. \& Zhang, J., 2008. The Issue of Robot Education in China's Basic Education and its Strategies. Chengdu, s.n. 